\title{
Evaluation of a species-specific C-reactive protein assay for the dog on the $A B X$ Pentra 400 clinical chemistry analyzer
}

Sarah Hindenberg ${ }^{1 *}$, Stefanie Klenner-Gastreich², Nicole Kneier², Sabine Zielinsky, Kris Gommeren³, Natali Bauer ${ }^{1}$ and Andreas Moritz ${ }^{1}$

\begin{abstract}
Background: A canine-specific immunoturbidimetric CRP assay, Gentian Canine CRP Immunoassay) with speciesspecific controls and calibrators was introduced and recently evaluated on the clinical chemistry analyzer Abbott Architect c4000 as well as on the Olympus AU600.

Aims of our study were 1) to independently evaluate the canine-specific CRP assay on the ABX Pentra 400 clinical chemistry analyzer in comparison to the previously validated human-based immunoturbidimetric assay (Randox Canine CRP assay) and 2) to assess the impact of different sample types (serum versus heparinized plasma) on the results. Imprecision, accuracy, interference and the prozone effect were determined using samples from healthy and diseased dogs $(n=278)$. The Randox Canine CRP assay calibrated with canine specific control calibration material served as a reference method. Additionally, the impact of the sample type (serum and lithium heparin) was evaluated based on samples of healthy and diseased dogs $(n=49)$ in a second part of the study.

Results: Linearity was present for CRP concentrations ranging from 4 to $281 \mathrm{mg} / \mathrm{l}$. For clinically relevant CRP concentrations of 7-281 mg/l, recovery ranged between 90 and 105\% and intra- and inter-assay CVs ranged between $0.68 \%-12.12 \%$ and $0.88 \%-7.84 \%$, respectively. CV was thus lower than $12.16 \%$, i.e. the desired CV\% based on biological variation. Interference was not present up to a concentration of $5 \mathrm{~g} / \mathrm{l} \mathrm{hemoglobin,} 800 \mathrm{mg} / \mathrm{l}$ bilirubin and $10 \mathrm{~g} / \mathrm{l}$ triglycerides. No prozone effect occurred up to $676 \mathrm{mg} / \mathrm{l}$ CRP. Method comparison study revealed a Spearman's rank correlation coefficient of $r_{s}=0.98$ and a mean constant bias of $5.2 \%$. The sample type had a significant $(P=0.008)$ but clinically not relevant impact on the results (median CRP of $30.9 \mathrm{mg} / \mathrm{l}$ in lithium heparin plasma versus $31.4 \mathrm{mg} / \mathrm{l}$ in serum).
\end{abstract}

Conclusions: The species-specific Gentian Canine CRP Immunoassay reliably detects canine CRP on the ABX Pentra 400 clinical chemistry analyzer whereby both serum and heparin plasma can be used. The quality criteria reached on the Abbott Architect c4000 and Olympus AU600 could be met.

Keywords: Acute phase protein, Canine, Method validation, Analyzer, Repeatability, Linearity, Total allowable error, Heparin plasma, Interference

\footnotetext{
* Correspondence: sarah.hindenberg@vetmed.uni-giessen.de

${ }^{1}$ Department of Veterinary Clinical Sciences, Clinical Pathology and Clinical

Pathophysiology, Justus-Liebig-University Giessen, 35392 Giessen, Germany

Full list of author information is available at the end of the article
} 


\section{Background}

C-reactive protein (CRP) is a major acute phase protein (APP) in the dog. As a part of innate immune response, APPs change their serum concentration in response to a systemic inflammation [1-4]. In contrast to classic inflammatory markers such as the white blood cell count, APPs react more rapidly and with a shorter half-life period $[1,5]$. According to their kinetics in response to a pathological stimulus, positive APPs are classified as major, moderate and minor APPs. While major APPs show a 100 - to 1000 -fold increase within $24-48 \mathrm{~h}$ and decrease rapidly, moderate APPs react with a 5- to 10fold increase within a period of 2-3 days and a slow decrease. In contrast, minor APPs react with a mild 1.5- to 2-fold increase [3]. Due to their marked, rapid increase, especially major APPs are sensitive diagnostic and prognostic measurands [6, 7] to monitor systemic inflammation. In dogs, an increase of CRP was shown in several conditions including infectious diseases [8-11], immune mediated diseases [12-14], neoplasias [12, 15, 16], and surgery [17].

A canine species-specific enzyme-linked immunosorbent assay (ELISA) [18] proved to be sensitive but too time-consuming to be used for routine measurements of canine CRP. First evaluation of immunoturbidimetric assays designed for the detection of human CRP showed unsatisfactory interspecies cross-reactivity between canine CRP and human CRP-antibodies [19], which was mainly attributed to a species-specific pattern of glycosylation of the CRP molecule [20, 21]. Later, an immunoturbidimetric assay with a reasonable cross-reactivity was evaluated [22].

In 2010, our group investigated three human-based immunoturbidimetric test systems in comparison to a species-specific ELISA [23]. However, application of human CRP reagents and heterologous control and calibration material may lead to unpredictable results with false low values in dog samples [22, 24]. The growing interest in standardizing and communicating the range of methods of APP measurement in veterinary species [2, 24, 25] led to the development of canine-specific assays with specific calibrators and controls. Meanwhile, purified canine CRP became commercially available and was used as calibrator in human CRP assays [24]. Canine specific controls as internal quality material still had to be prepared out of serum pools of healthy and diseased patients.

Recently, a species-specific immunoturbidimetric assay for canine CRP (Gentian Canine CRP Immunoassay, Gentian AS, Moss, Norway) became available and had been validated by Hillström et al. 2014 on the Abbott Architect c4000 (Abbott Park, IL, USA) in comparison to the Randox Canine CRP assay [26]. However, quality performance differences between various clinical chemistry analyzers have been demonstrated previously [27] making it difficult to both generalize results and compare studies. Muñoz-Prieto et al. investigated the same assay run on an Olympus AU600 analyzer but used the heterologous Olympus CRP assay as a reference method [28]. Apart from the analyzer, the sample material might also have an impact on assay performance. Acute phase proteins are commonly measured in serum, however, sometimes only either serum or lithium heparin plasma samples are submitted, when a clinical chemistry profile including CRP is requested. Unfortunately it is not always possible to collect a further comparable sample. It is therefore important to determine if both sample materials can be used interchangeably.

To the authors' knowledge, the impact of the ABX Pentra 400 as a different analyzer on the performance of the Gentian CRP test as well as the effect of the sample material (serum versus heparin plasma) has not been evaluated so far. The aim of our study was thus to validate this assay with a different analyzer (i.e, Pentra 400 analyzer compared to the Abbott Architect c4000 and Olympus AU600 analyzer, respectively) using a similar methodology as the previous studies.

Our hypothesis was that the automated analyzer used has only a minor impact on the test performance; however, the sample material (heparin plasma versus serum) cannot be used interchangeably.

\section{Methods \\ Study design}

The present validation study was conducted between April 2013 and March 2016.

The study was structured into two parts: First, method validation was performed, including the evaluation of accuracy, recovery, precision, interference, prozone effect, and method comparison. The method comparison study was conducted according to recent recommendations [29], whereby the previously validated human-based immunoturbidimetric Randox Canine CRP assay (Randox Laboratories Ltd., Crumlin, UK) [23] served as the reference method. In the second part comparative measurements between lithium heparin plasma and serum samples were conducted to assess potential influence of an anticoagulant in order to simplify future routine diagnostics by allowing the application of both serum and heparin plasma samples.

\section{Measurement of C-reactive protein}

Both the Gentian Canine CRP Immunoassay and the Randox Canine CRP assay were run on the ABX Pentra 400 clinical chemistry analyzer (Horiba ABX SAS, Montpellier, France).

\section{Gentian canine CRP immunoassay}

The canine-specific CRP assay (Gentian Canine CRP Immunoassay, Gentian AS, Moss, Norway) designed to be 
run on an automated analyzer is a quantitative immunoturbidimetric in-vitro diagnostic test using polyclonal chicken-derived canine-specific anti-CRP antibodies. The anti-CRP-immunoparticles aggregate with canine CRP and form complexes that can be measured with turbidimetric methods and are correlated with canine CRP concentrations by interpolation on a calibration curve. Calibration (Gentian Canine CRP Calibrator Kit, Gentian AS, Moss, Norway) and the measurement of canine-specific control material serving as internal quality control (Gentian Canine CRP Control Kit, Gentian AS, Moss, Norway) were performed daily.

\section{Randox canine CRP assay}

In our study, LOT 1303404 of Randox Canine CRP assay and - in contrast to the previous validation study [23] but in accordance with the previous validation study for the Gentian Canine CRP assay using the Randox Canine CRP assay as the reference method - a canine calibrator (Canine CRP Life Diagnostics, Inc., West Chester, USA) was used. Using canine calibration material for the human-based Randox Canine CRP assay, intra-assay CV ranged between $0.7 \%-2.1 \%$ (unpublished data).

Measurements were performed as batch analysis at one day. Canine-specific calibration (Canine CRP Life Diagnostics, Inc., West Chester, USA) was done before the analyses were started while canine-specific control measurements (Canine CRP Reference Standard Biozol Diagnostica Vertrieb GmbH, Eching, Germany) were performed prior to the analyses and after each measurement of 60 samples.

\section{Method validation}

To avoid preanalytical error due to numerous dilution steps, as it may occur by serially diluting a sample with very high CRP concentration to achieve a very low CRP concentration, linearity was evaluated in two dilution experiments with a partially overlapping CRP range: Linearity was first assessed by manual dilution of a canine serum specimen with markedly increased CRP concentration of $281.3 \mathrm{mg} / \mathrm{l}$, achieving samples with 1.0, 0.8 , $0.6,0.4,0.2,0.1,0.05$, and 0.025 of the original CRP concentration. In addition, the diluted samples were used to calculate the recovery rate at eight different CRP levels.

To gain more information about the test performance at low CRP concentrations, linearity was also assessed by manual, stepwise dilution of pooled canine quality control material, whereby a normal and an abnormal control were mixed in equal parts (Gentian Canine CRP Control Kit, Gentian AS, Moss, Norway) so that a pooled sample with a mean CRP concentration of $66.5 \mathrm{mg} / \mathrm{l}$ was obtained that was then serially diluted to assess linearity at low CRP concentrations. For all dilution steps, double-distilled water was used as diluent to achieve samples with 1.0, 0.8,
0.6, 0.4, 0.2, 0.1, 0.05, 0.025 and 0.0125 of the original CRP concentration of the pooled samples. All samples were analyzed in triplicates in a single run. Intra-assay and interassay repeatability including between-run and betweenday $\mathrm{CV}$ were determined by measurement of four canine serum samples with different CRP concentrations (A: $7.2 \mathrm{mg} / \mathrm{l}$, B: $58.4 \mathrm{mg} / \mathrm{l}$, C: $103.9 \mathrm{mg} / \mathrm{l}, \mathrm{D}: 272.1 \mathrm{mg} / \mathrm{l})$. Sample analysis was carried out in duplicates twice daily (morning and evening to assess between-run CV) over 5 days without recalibration. Sample order was changed randomly every run.As recommended for a verification of the limit of quantification [30], additional measurements were performed to evaluate intra-assay precision specifically for CRP values close to zero (A1: $2.3 \mathrm{mg} / \mathrm{l}$, A2: $3.8 \mathrm{mg} / \mathrm{l})$. Here, samples were analyzed 20 times in a single run without recalibration.

Interference was investigated by spiking aliquots of a canine serum sample of $35.5 \mathrm{mg} / \mathrm{l} \mathrm{CRP}$ with $800 \mathrm{mg} / \mathrm{l}$ bilirubin (Bilirubin, Sigma-Aldrich Co. LLC., St. Louis, Missouri, USA), $5 \mathrm{~g} / \mathrm{l}$ hemoglobin (Hemoglobin human, Sigma-Aldrich Co. LLC., St. Louis, Missouri, USA) or $10 \mathrm{~g} / \mathrm{l} 20 \%$ soy bean emulsion (Intralipid 20\%, Fresenius Kabi Canada, Ontario, Canada) before analyzing them in triplicates in random order.

A stock solution containing bilirubin in a concentration of $20 \mathrm{~g} / \mathrm{l}$ was prepared by diluting $20 \mathrm{mg}$ bilirubin in $1 \mathrm{ml}$ of $0.1 \mathrm{M} \mathrm{NaOH}$. Then, $0.1 \mathrm{ml}$ of the product was added to $2.4 \mathrm{ml}$ non-spiked serum sample to achieve a bilirubin level of $800 \mathrm{mg} / \mathrm{l}$.Lyophilized human hemoglobin was dissolved in $0.09 \% \mathrm{NaCl}(1$ part in 10 parts of $\mathrm{NaCl})$ so that a stock solution containing $100 \mathrm{~g} / \mathrm{l}$ hemoglobin was obtained and $0.125 \mathrm{ml}$ of the solution were added to $2.375 \mathrm{ml}$ non-spiked serum sample to receive a hemoglobin concentration of $5 \mathrm{~g} / \mathrm{l}$.To assess the impact of lipemia on results, $0.125 \mathrm{ml}$ of Intralipid were added to $2.375 \mathrm{ml}$ of non-spiked serum sample resulting in concentration of soya bean oil of $10 \mathrm{~g} / \mathrm{l}$.

The samples were compared to serum aliquots spiked with an equal volume of either $100 \mathrm{mM} \mathrm{NaOH}$ (in case of bilirubin), $0.09 \% \mathrm{NaCl}$ (hemoglobin) or pure water (in case of Intralipid). Antigen overload may provoke falsely low CRP measurements. This so called prozone effect was evaluated by spiking a serum sample containing a very low CRP concentration with purified canine CRP (Dog C-Reactive Protein, Life Diagnostics, Inc., WestChester, USA) until a CRP concentration of $1069.5 \mathrm{mg} / \mathrm{l}$ was obtained. The spiked sample was subsequently diluted with $0.9 \% \mathrm{NaCl}$ so that final concentrations of $455 \mathrm{mg} / \mathrm{l}, 676 \mathrm{mg} / \mathrm{l}$, and $890 \mathrm{mg} / \mathrm{l}$ were achieved. Samples were measured in duplicates in a single run.

\section{Method comparison study}

In the method comparison study, the Gentian Canine CRP Immunoassay was compared to the previously 
validated human-based immunoturbidimetric Randox Canine CRP assay.

Overall, 278 serum samples of healthy and diseased dogs presented at the Department of Clinical Sciences, School of Veterinary Medicine, University of Liège, Liège, Belgium, were analyzed with both immunoturbidimetric assays. The samples have already been used for a previous study in which inflammatory cytokines and CRP were investigated in canine systemic inflammatory response syndrome patients [31]. In our study, residual sample material was used.

Samples were collected between January and August 2010, stored at $-80{ }^{\circ} \mathrm{C}$ and shipped frozen to the Department of Veterinary Clinical Sciences, Clinical Pathology and Clinical Pathophysiology, Justus-Liebig-University Giessen, Germany, and stored again at $-80{ }^{\circ} \mathrm{C}$ for 4 weeks until batch-analysis was performed.

\section{Effect of sample material}

To assess the impact of an anticoagulant (lithium heparin plasma versus serum sample) on the CRP measurements, blood samples of 49 healthy and diseased dogs presented at the Clinic for Small Animals, Faculty of Veterinary Medicine, Justus-Liebig University, Giessen, Germany, were obtained simultaneously by venipuncture with a sterile disposable cannula into tubes $(1.3 \mathrm{ml})$ containing lithium heparin as anticoagulant and tubes without additives.

Inclusion criterion was that both a heparinized blood sample and a serum sample were taken for diagnostic purposes. Between March and April 2014, samples were analyzed in matched pairs within the first hour after blood collection. Lithium heparin anticoagulated samples were centrifuged for $1 \mathrm{~min}$ with $8944 \mathrm{~g}$ without delay, while samples without additives were allowed to clot for at least $10 \mathrm{~min}$ after receipt in the laboratory. Intra-assay repeatability for measurement of CRP in heparinized plasma was first assessed for ten consecutive measurements with samples from three dogs with low, moderate and high CRP values (10, 53, $77 \mathrm{mg} / \mathrm{l}$ respectively). Additionally, the LoQ of the CRP assay determined for serum (A1, A2, Table 1) was verified for heparinized plasma as well, whereby both the heparinized and the serum samples were taken from the same dogs with CRP values close to zero and analyzed 20 times.

\section{Statistical analysis}

Statistical analyses were carried out using statistical software packages (MedCalc, software version 16.2.1; Ostend, Belgium and GraphPad Prism 6 Software, GraphPad Software, Inc., La Jolla, USA).

\section{Method validation study}

Limits of acceptance were set according to Total allowable error (TE) guidelines of the American college of Veterinary Clinical Pathology (ASVCP) [32]. Although no definite TE for CRP was recommended by the workgroup, an optimal and desired coefficient of variation $(\mathrm{CV})$, bias, and TE based on biologic variation was given in the addendum of the ASVCP guidelines: The optimal / desired allowable imprecision $\left(\mathrm{CV}_{\text {opt }} / \mathrm{CV}_{\text {des }}\right)$ were reported to be $6.08 \%$ and $12.16 \%$ respectively, the optimal and desired allowable bias ( bias $_{\text {opt }} /$ bias $_{\text {des }}$ ) were $4.76 \% /$ 9.52\% and the optimal / desired total allowable error $\left(\mathrm{TE}_{\mathrm{opt}} / \mathrm{TE}_{\mathrm{des}}\right)$ were $14.79 \% / 29.58 \%$, respectively [32]. Here, numbers rounded to one decimal place are used.

Descriptive statistics were performed to calculate arithmetic means, standard deviations (SD), and CV. All data were evaluated for normal distribution using the Shapiro-Wilk Test.

To evaluate the linearity under dilution of the assay, mean results of measured values were plotted against

Table 1 Precision of CRP determination in pooled serum samples with CRP concentrations below a clinical decision limit (A1 - A2) as well as pooled serum samples with clinically relevant CRP concentrations

\begin{tabular}{|c|c|c|c|c|c|c|c|}
\hline \multirow{2}{*}{$\overline{\text { Level }}$} & \multirow[b]{3}{*}{$\begin{array}{l}\text { Mean } \\
\text { CRP concentration } \\
\text { (mg/l) }\end{array}$} & \multirow{2}{*}{\multicolumn{2}{|c|}{ Intra-assay CV }} & \multicolumn{4}{|c|}{ Inter-assay CV } \\
\hline & & & & \multicolumn{2}{|c|}{ Between run CV } & \multicolumn{2}{|c|}{ Between day CV } \\
\hline & & $\mathrm{SD}(\mathrm{mg} / \mathrm{l})$ & CV\% & $\mathrm{SD}(\mathrm{mg} / \mathrm{l})$ & CV\% & $\mathrm{SD}(\mathrm{mg} / \mathrm{l})$ & CV\% \\
\hline $\mathrm{A} 1$ & 2.3 & 0.72 & 31.1 & n.d. & n.d. & n.d. & n.d. \\
\hline$A 2$ & 3.8 & 0.35 & 9.3 & n.d. & n.d. & n.d. & n.d. \\
\hline A & 7.2 & 0.87 & 12.1 & 0.56 & 7.8 & 0.44 & 6.1 \\
\hline B & 58.4 & 1.08 & 1.9 & 1.25 & 2.1 & 2.7 & 4.6 \\
\hline C & 103.9 & 0.88 & 0.9 & 0.91 & 0.9 & 1.9 & 1.8 \\
\hline$D$ & 272.1 & 1.85 & 0.7 & 4.98 & 1.8 & 2.8 & 1.1 \\
\hline
\end{tabular}

A1, A2: CVs for intra-assay imprecision of two canine serum pools analyzed 20 times in a single run without recalibration.

A - D: Inter- and intra-assay CVs of 6 canine serum pools analyzed in duplicates twice daily over 5 days.

CVs not fulfilling the quality specifications i.e., are higher than $12.2 \%$ [32] are marked in bold letters.Abbreviations: n.d. $=$ not done, SD $=$ standard deviation; $\mathrm{CV}=$ coefficient of variation. 
theoretical CRP concentration. The 'best fit' line was visually inspected for linearity. In addition, recovery after dilution was calculated by subtracting the measured CRP result from the calculated (expected) CRP concentration according to the following formula:

Recovery $\%=\frac{\text { measuredconcentration-expectedconcentration }}{\text { expectedconcentration }} x 100$.

Acceptance criteria for recovery rates were set at 80 $120 \%$ for samples as recommended previously for validation of immunoassays [33, 34]. The intra-assay CVs were calculated as follows based on mean and standard deviation (SD):

\section{$\mathrm{CV} \%=\frac{S D}{\text { Mean }} \times 100$}

For the interference study, non-spiked samples (control) and samples spiked with the interfering substances (test) were measured in triplicates. Observed interference effect $\left(\mathrm{d}_{\mathrm{obs}}\right)$ was computed as the \% bias between the means of the test and control specimens:

\section{$\mathrm{d}_{\text {obs }} \%=\frac{\text { meantest-meancontrol }}{\text { meancontrol }} \times 100$}

In accordance with the literature, bias between control and test sample was considered acceptable if the bias for the interfering substance (i.e., $d_{\text {obs }} \%$ ) was smaller than the allowable $\mathrm{TE}$ [35], i.e. $29.6 \%\left(\mathrm{TE}_{\mathrm{des}}\right)$, and $14.8 \%$ $\left(\mathrm{TE}_{\text {opt }}\right)$ for canine CRP [32].

\section{Method comparison study}

Data of the method comparison experiment were analyzed with Spearman's rank correlation and Passing \& Bablok regression analysis. Bland-Altman difference plot was performed to investigate $\%$ bias. In addition, the total observed error $\mathrm{TE}_{\mathrm{obs}}$ was calculated to judge acceptability according to the quality specifications recommended by the American Society for Veterinary Clinical Pathology (ASVCP) [32]. TE $\mathrm{Tbs}_{\mathrm{os}}$ was calculated using following formula:

$$
\mathrm{TE}_{\mathrm{obs}}=\text { bias } \%+2 \mathrm{CV} \% \text {. }
$$

\section{Effect of sample material}

Comparative measurements of plasma samples: Normality was assessed with a Shapiro Wilk test. Since data were not normally distributed, Wilcoxon signed-rank test was performed to assess potential differences between the methods. For method validation, Spearman's rank correlation as well as Passing-Bablok regression and Bland-Altman analysis were performed.

\section{Results}

\section{Method validation study}

Results of the precision study are shown in Table 1. For clinically relevant CRP concentrations ranging between 7.2 and $272.1 \mathrm{mg} / \mathrm{l}$ (concentrations A-D), both intraand inter-assay CVs fulfilled the quality specifications, i.e., the CVs did not exceed $12.2 \%$ [32]. Intra-assay imprecision $<2 \%$ was present for clinically relevant CRP- ranges $>40 \mathrm{mg} / \mathrm{l}$. Only for CRP concentrations of $2.5 \mathrm{mg} / \mathrm{l}$, a CV markedly exceeding the desired CV was noted, so that the LoQ was set above the lowest concentrations still fulfilling the quality specifications i.e., $3.8 \mathrm{mg} / \mathrm{l}(\approx 4 \mathrm{mg} / \mathrm{l})$. Evaluation of inter-assay precision showed slightly higher inter-assay CVs of $0.88-7.84 \%$ than intra-assay CVs.

The results of the linearity study for higher and lower concentration ranges are demonstrated in Fig. 1, Table 2, and Table 3. As shown in Fig. 1, there was an excellent correlation between expected and measured values for both concentrations ranges. Considering the LoQ, linearity under dilution of the Gentian Canine CRP Immunoassay was present in a range of 4-281 $\mathrm{mg} / \mathrm{l}$ for serially diluted canine specimens (Figure 1). Recovery rate ranged between $88.9-105.4 \%$ at expected CRP values of 7.0-281.3 mg/l (Table 2) and thus fulfilling the quality requirements. For CRP concentrations ranging between $0.8 \mathrm{mg} / \mathrm{l}$ and $66.5 \mathrm{mg} / \mathrm{l}$ (Table 3), however, quality requirements were not fulfilled for the lowest CRP concentrations of $0.8 \mathrm{mg} / \mathrm{l}$ and $1.7 \mathrm{mg} / \mathrm{l}$, respectively.

Overall, no interference was detectable up to a concentration of $5 \mathrm{~g} / \mathrm{l}$ hemoglobin, $800 \mathrm{mg} / \mathrm{l}$ bilirubin and $10 \mathrm{~g} / \mathrm{l}$ soy bean oil (Table 4). Mean absolute bias between control and spiked test samples was $0.1 \mathrm{mg} / \mathrm{l}, 0.6 \mathrm{mg} / \mathrm{l}$ and $1.6 \mathrm{mg} / \mathrm{l}$ respectively. At a clinically relevant CRP concentration of about $30 \mathrm{mg} / \mathrm{l}$, the systematic errors are lower than $\mathrm{TE}_{\mathrm{opt}}$ for all interfering substances. No prozone effect was present up to a concentration of $676 \mathrm{mg} / \mathrm{l} \mathrm{CRP} \mathrm{as}$ CRP values were measured correctly: The recovery rates for high CRP concentrations were $130 \%$ for $455 \mathrm{mg} / \mathrm{l}$, $121 \%$ for $676 \mathrm{mg} / \mathrm{l}$ and $28 \%$ for $890 \mathrm{mg} / \mathrm{l}$, respectively.

\section{Method comparison study}

As demonstrated in Fig. 2, there was an excellent correlation $\left(r_{s}=0.98\right)$ between the results obtained with the species specific canine CRP test and the reference method. Passing-Bablok regression equation revealed small constant and proportional errors reflected by an intercept of -1.18 (with $95 \%$ confidence intervals (CI) of -2.07 to $-0.43 \mathrm{mg} / \mathrm{l})$ and a slope of 0.99 (95\% CI 0.97 to 1.08) (Figure 2). Bland-Altman analysis revealed a mean constant bias of $5.2 \%$ (Figure 3). Taking the bias and the inter-assay $\mathrm{CV}$ at the 4 different CRP concentrations (A$\mathrm{D}$, Table 1) under consideration, $\mathrm{TE}_{\mathrm{obs}}$ was calculated and results are shown in Table $5 . \mathrm{TE}_{\mathrm{obs}}$ ranged from $20.9 \%$ at low levels to $7.0-9.5 \%$ at higher levels B-D (table 5). Overall, $\mathrm{TE}_{\mathrm{obs}}$ was $<\mathrm{TE}_{\mathrm{des}}$ of $29.6 \%$ for all CRP concentration levels and even $<\mathrm{TE}_{\mathrm{opt}}$ of $14.8 \%$ for the clinically relevant concentration levels B-D [32].

\section{Effect of sample material}

Spearman's rank correlation coefficient revealed an excellent correlation between CRP measurements obtained 

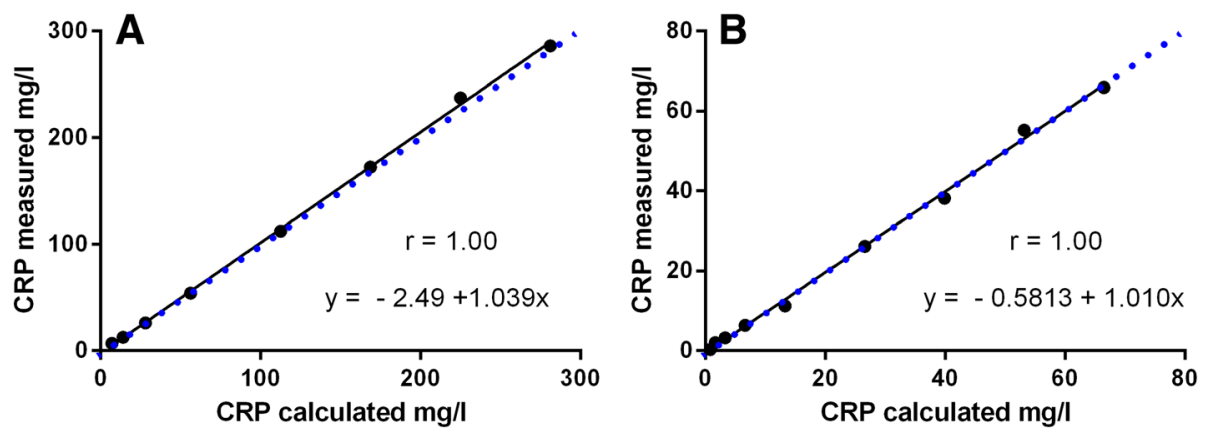

Fig. 1 Linearity of CRP determination at a high (a) and low concentration range (b). (a) Linearity under dilution for measurement of a canine serum sample originally containing $281.3 \mathrm{mg} / \mathrm{I}$ CRP. A serial dilution was performed to achieve 8 different CRP concentrations, i.e., 1.0, 0.8, 0.6, 0.4, $0.2,0.1,0.05,0.025$ parts of the original concentration (b) Linearity range of CRP determination for a canine serum sample containing $66.5 \mathrm{mg} / \mathrm{l}$ CRP. A serial dilution was performed to achieve 9 different CRP concentrations i.e., 1.0, 0.8, 0.6, 0.4, 0.2, 0.1, 0.05, 0.025, 0.0125 parts of the original concentration

in serum and heparin plasma samples $\left(\mathrm{r}_{\mathrm{s}}=0.995\right)$. There was a significant $(P=0.008)$, but clinically not relevant difference between the median CRP results obtained for both sample types (30.9 mg/l for lithium heparin plasma versus $31.4 \mathrm{mg} / \mathrm{l}$ for serum samples).Passing-Bablok regression equation showed a small constant error with an intercept of 0.29 and a small proportional error with a slope of 0.97 (Figure 4). Bland-Altman difference plot (Figure 5) revealed a mean bias of $4.3 \%$ between results obtained with both sample types.

\section{Discussion}

Overall, the Gentian Canine CRP Immunoassay accurately and precisely detects canine CRP similar to the previously used human-based immunoturbidimetric method on the ABX Pentra 400 clinical chemistry analyzer.

Comparisons of results of the current and previous studies evaluating the Gentian CRP test for different analyzers are shown in Table 6. As seen in the table, comparable results have been obtained for the majority of quality parameters demonstrated on the Abbott Architect c4000 [26] so that performance quality could be also confirmed for the ABX Pentra 400. There are some small differences that have the potential to be clinically relevant including a different CRP concentration at which a prozone effect occurs, a slightly different LoQ and a different linearity range (table 6). The evaluation on the Olympus AU600 revealed a LoQ lying between the values of the other two studies (table 6). Linearity and prozone effect were not investigated in comparably high ranges as performed in the other studies. It remains unclear if the differences between the studies are due to pre-analytic or analytic factors. As such, evaluation of these discrepant quality parameters for different types of analyzer across laboratories is recommended. The main discrepancy between the current and the study by Hillström et al. is the CRP concentration at which a prozone effect is seen which is markedly higher $(1200 \mathrm{mg} / \mathrm{l})$ in the previous than in the current study $(676 \mathrm{mg} / \mathrm{l})$. Muñoz-Prieto et al. mentioned the prozone effect to occur above a CRP level of $400 \mathrm{mg} / \mathrm{l}$ but did not

Table 2 Linearity and recovery rates of CRP measurements in a clinically relevant range of 7.0-281.3 mg/l after serial dilution of a canine serum sample containing $281.3 \mathrm{mg} / \mathrm{l}$ CRP

\begin{tabular}{|c|c|c|c|c|c|c|}
\hline $\begin{array}{l}\text { Dilution } \\
\text { Factor }\end{array}$ & $\begin{array}{l}\text { Expected concentration } \\
{[\mathrm{mg} / \mathrm{l}]}\end{array}$ & $\begin{array}{l}\text { Mean measured } \\
\text { concentration[mg/l] }\end{array}$ & $\begin{array}{l}\text { Recovery } \\
{[\%]}\end{array}$ & Bias[\%] & $\begin{array}{l}\% \text { bias }<\mathrm{TE}_{\text {des }} \\
(29.6 \%)\end{array}$ & $\begin{array}{l}\% \text { bias }<\mathrm{TE}_{\mathrm{opt}} \\
(14.8 \%)\end{array}$ \\
\hline 0.025 & 7.0 & 6.9 & 97.6 & -2.4 & Yes & Yes \\
\hline 0.05 & 14.1 & 12.5 & 88.9 & -11.1 & Yes & Yes \\
\hline 0.1 & 28.1 & 26.1 & 92.9 & -7.1 & Yes & Yes \\
\hline 0.2 & 56.3 & 54.1 & 96.1 & -3.9 & Yes & Yes \\
\hline 0.4 & 112.5 & 112.3 & 99.8 & -0.2 & Yes & Yes \\
\hline 0.6 & 168.8 & 172.3 & 102.1 & 2.2 & Yes & Yes \\
\hline 0.8 & 225.0 & 237.3 & 105.4 & 5.4 & Yes & Yes \\
\hline 1 & 281.3 & 286.2 & 101.7 & 1.7 & Yes & Yes \\
\hline
\end{tabular}

Recovery rates not fulfilling the quality specifications of $80-120 \%$ are marked in bold letters as well as \% bias between expected and measured mean CRP concentration exceeding the desired $\left(\mathrm{TE}_{\mathrm{des}}\right)$ and optimal total allowable error $\left(\mathrm{TE}_{\mathrm{opt}}\right)$ reported previously [32]. 
Table 3 Linearity and recovery rates of CRP measurements at a lower concentration range of 0.8-66.5 mg/l obtained after serial dilution of a canine serum sample containing $66.5 \mathrm{mg} / \mathrm{l} \mathrm{CRP}$

\begin{tabular}{|c|c|c|c|c|c|c|}
\hline $\begin{array}{l}\text { Dilution } \\
\text { Factor }\end{array}$ & $\begin{array}{l}\text { Expected concentration } \\
{[\mathrm{mg} / \mathrm{l}]}\end{array}$ & $\begin{array}{l}\text { Mean measured } \\
\text { concentration[mg/l] }\end{array}$ & $\begin{array}{l}\text { Recovery } \\
{[\%]}\end{array}$ & Bias[\%] & $\begin{array}{l}\% \text { bias }<\mathrm{TE}_{\text {des }} \\
(29.6 \%)\end{array}$ & $\begin{array}{l}\% \text { bias }<\mathrm{TE}_{\mathrm{opt}} \\
(14.8 \%)\end{array}$ \\
\hline 0.0125 & 0.8 & 0.3 & 36.1 & -63.9 & No & No \\
\hline 0.025 & 1.7 & 2.0 & 122.5 & 22.5 & Yes & No \\
\hline 0.05 & 3.3 & 3.3 & 98.4 & -1.6 & Yes & Yes \\
\hline 0.1 & 6.7 & 6.4 & 95.7 & -4.3 & Yes & Yes \\
\hline 0.2 & 13.3 & 11.2 & 84.3 & -15.7 & Yes & Yes \\
\hline 0.4 & 26.6 & 26.2 & 98.6 & -1.4 & Yes & Yes \\
\hline 0.6 & 39.9 & 38.1 & 95.6 & -4.4 & Yes & Yes \\
\hline 0.8 & 53.2 & 55.3 & 103.9 & 3.9 & Yes & Yes \\
\hline 1 & 66.5 & 65.9 & 99.2 & -0.8 & Yes & Yes \\
\hline
\end{tabular}

For quality specifications regarding recovery rate and \% bias, see Table 2.

evaluate higher levels [28]. The term prozone effect describes the event of false low values of the analyte in immunoassays due to an excess of the analyte and is based on the saturation curve of the antibody binding capacity for antigen. The high number of analyte particles inhibits the formation of antigen-antibody complexes as all binding sites of the antibody are already occupied by antigen. This mechanism can lead to a false low signal detected by turbidimetry [36]. Regarding the origin of the markedly different prozone effect observed here and in the previous study, pre-analytic factors such as pipetting errors are considered an unlikely cause. However, analytical factors including analyzer performance, variations in test application or differences between variable batches of the test are a likely explanation for the discrepant prozone effect between the studies. Marked batch-specific differences in test performance due to manufacturing tolerances have been previously observed for the human Randox CRP assay when applied for canine specimens $[23,24]$. However, the marked variation between different batches of the CRP assay was mainly caused by the highly variable cross-reactivity between anti-human-CRP antibodies applied in the test and canine CRP. In a canine species-specific CRP test, such high variation is unlikely, however, differences between various batches have to be evaluated in future studies. Another possible explanation would be a variation between different batches of calibrators which could influence the calibration curve in detail and therefore cause small differences in CRP values reported. It is a limitation of this study that it was not possible to directly compare the performance of both analyzers using the same batch of test reagents, calibrators and samples to exclude batch related variances. The instrument settings of the different analyzers used may contribute to a variation of the CRP-concentration causing a prozone effect. If the recommended standard instrument settings [37] are used, however, no major differences between the settings can be found. There is no pre-dilution of the sample by both analyzers which could potentially influence a prozone effect. Moreover, minor differences between the analyzers such as a minimally different measuring wave length $(600 \mathrm{~nm}$ for the ABX Pentra 400, $604 \mathrm{~nm}$ for Abbott Architect c4000) are unlikely to have a major impact on the occurrence of a prozone effect.

The use of latex particles reduces prozone effects [36] as well as an endpoint measurement instead of a kinetic analysis, but both factors were constant here as the same assay was used on both analyzers.

In contrast, a different reagent volume and ratio of reagent to sample volume ( $270 \mu \mathrm{l}$ of reagent $1,75 \mu \mathrm{l}$ of reagent 2, $3 \mu \mathrm{l}$ sample volume for the ABX Pentra 400; $270 \mu \mathrm{l}$ of reagent $1,70 \mu \mathrm{l}$ of reagent $2,2 \mu \mathrm{l}$ sample volume for Abbott Architect c4000) may be a possible explanation for different CRP concentrations at which a prozone effect occurs but it remains questionable if it is

Table 4 Interference effects of hemoglobin, bilirubin and lipid (soya bean oil) on CRP measurement performed with the new automated species-specific immunoturbidimetric assay

\begin{tabular}{|c|c|c|c|c|c|c|}
\hline Interferent & $\mathrm{CRP}_{\text {control }}[\mathrm{mg} / \mathrm{l}] \pm \mathrm{SD}$ & $\mathrm{CRP}_{\text {test }}[\mathrm{mg} / \mathrm{l}] \pm \mathrm{SD}$ & Mean bias [mg/l] & $\%$ bias & $\%$ bias < $\mathrm{TE}_{\mathrm{des}}(29.6 \%)$ & $\%$ bias $<\mathrm{TE}_{\text {opt }}(14.8 \%)$ \\
\hline Hemoglobin $5 \mathrm{~g} / \mathrm{l}$ & $33.7 \pm 0.7$ & $34.3 \pm 1$ & 0.57 & 1.7 & Yes & Yes \\
\hline Bilirubin 800 mg/l & $34.8 \pm 0.6$ & $34.9 \pm 1$ & 0.13 & 0.37 & Yes & Yes \\
\hline Soy bean emulsion $10 \mathrm{~g} / \mathrm{l}$ & $32.7 \pm 0.2$ & $34.4 \pm 1$ & 1.63 & 5.0 & Yes & Yes \\
\hline
\end{tabular}

Test samples $\left(\mathrm{CRP}_{\text {test }}\right)$ with a mean CRP value of $35.5 \mathrm{mg} / \mathrm{l}$ spiked with the interfering substances were measured in triplicates and compared to control samples $\left(\mathrm{CRP}_{\text {control }}\right)$ spiked with equal amounts of the diluent used in the test sample. \%Bias for the interfering substance was considered acceptable when it was < desired total allowable error $\left(\mathrm{TE}_{\mathrm{des}}\right)$ and excellent when it was < optimal total allowable error $\left(\mathrm{TE}_{\mathrm{opt}}\right)$ reported previously [32]. 


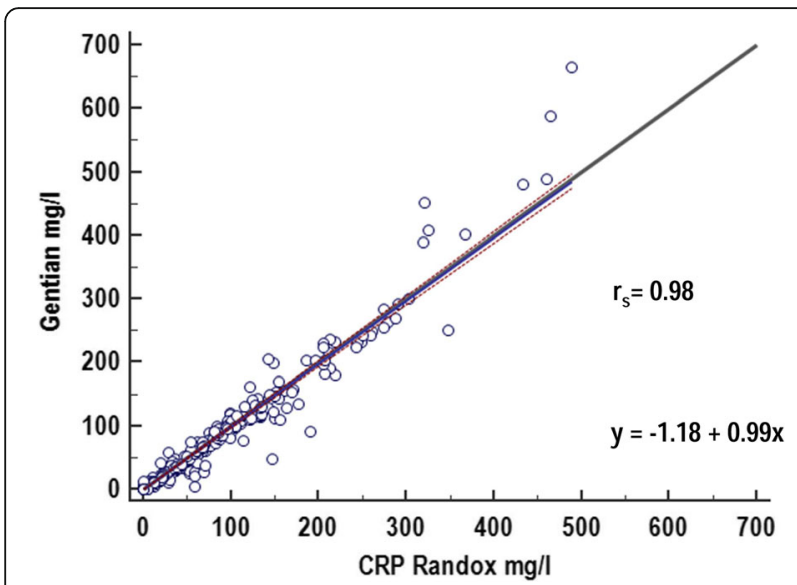

Fig. 2 Passing-Bablok regression analysis for canine C-reactive protein determined in canine serum samples by use of a species-specific immunoturbidimetric assay (Gentian Canine CRP Immunoassay) in comparison to a previously validated human based immunoturbidimetric test system (Randox Canine CRP assay) run with a dog calibrator. The solid blue line illustrates the regression equation with its 95\%-confidence intervals (brown dotted line). The thin solid grey line represents the identity line consistent with a perfect correlation of the two methods

the only explanation for the major differences between prozone effects observed in the different studies. Although CRP concentrations $>680 \mathrm{mg} / \mathrm{l}$ are extremely rare, septic dogs have been occasionally shown to have high CRP ranges of up to $632 \mathrm{mg} / \mathrm{l}[6]$ and in dogs with

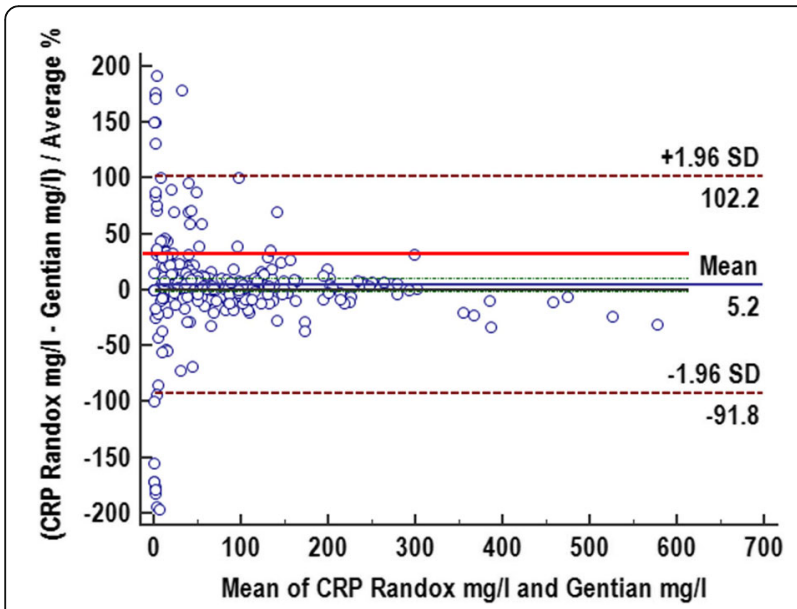

Fig. 3 Bland-Altman difference plot for canine C-reactive protein measured in canine serum samples with a new species-specific immunoturbidimetric assay (Gentian Canine CRP Immunoassay) in comparison to a validated human based test system (Randox Canine CRP assay). The solid blue line demonstrates the mean \% bias, the thin solid grey line is consistent with the identity line. The dashed brown lines show the limits of agreement, which are defined as the mean difference plus and minus 1.96 times the standard deviation (SD). The solid red line indicates the desired total allowable error $\left(\mathrm{TE}_{\text {des }}\right)$ of $29.6 \%$ [32]. A small bias of $5.2 \%$ with a confidence interval of $95 \%$ (green dotted lines) is present
Table 5 Observed total allowable error (TE $\mathrm{TEbs}_{\mathrm{ob}}$ ) calculated at four different CRP levels taking the coefficient of variation (CV) and the bias of $5.2 \%$ derived from the method validation study under consideration

\begin{tabular}{lllll}
\hline Level & $\mathrm{A}$ & $\mathrm{B}$ & $\mathrm{C}$ & $\mathrm{D}$ \\
\hline $\mathrm{CRP}$ concentration mg/l & 7.2 & 58.8 & 103.9 & 272.1 \\
$\mathrm{CV}_{\text {Between-run } \%}$ & 7.84 & 2.14 & 0.88 & 1.83 \\
$\mathrm{TE}_{\mathrm{obs}} \%$ & $\mathbf{2 0 . 9}$ & 9.5 & 7.0 & 8.9 \\
$\mathrm{TE}_{\mathrm{obs}}<\mathrm{TE}_{\text {des }}$ & Yes & Yes & Yes & Yes \\
$\mathrm{TE}_{\mathrm{obs}}<\mathrm{TE}_{\mathrm{opt}}$ & No & Yes & Yes & Yes \\
\hline
\end{tabular}

$\mathrm{TE}_{\text {obs }}$ was < desired total error ( $\mathrm{TE}_{\text {des }}$ ) of 29.6\% [32] for all CRP concentration levels. $\mathrm{TE}_{\mathrm{obs}} \%$ results exceeding the optimal $\mathrm{TE}\left(\mathrm{TE}_{\mathrm{opt}}\right)$ of $14.8 \%$ [32] are marked in bold letters.

snake envenomation even CRP concentrations above $900 \mathrm{mg} / \mathrm{l}$ were detected [38].As the prozone effect was shown to occur above a CRP concentration of $680 \mathrm{mg} / \mathrm{l}$, the issue of false low results in patients with these rarely occurring extremely high CRP values is a consideration. A correlation with other clinical and laboratory parameters is therefore mandatory to detect samples needing a pre-dilution before measurement.

The LoQ determined in the current study was slightly lower than the LoQ determined in previous validation studies [26, 28] (Table 6). In the current study, the LoQ was derived solely from the replication experiment, i.e. the quality goal was based on the $\mathrm{CV}_{\text {des }}$ published in the addendum of the allowable total error guidelines of the ASVCP [32] that had to be $<12.16 \%$. Muñoz-Prieto et al. used a higher $\mathrm{CV}$ of $<20 \%$ as decision criterion [28]. The LoQ in the previous study by Hillström et al. was obtained from the linearity experiment taking both the $\mathrm{CV}$ and the bias between expected and measured values into consideration, i.e. the quality goal was based on the

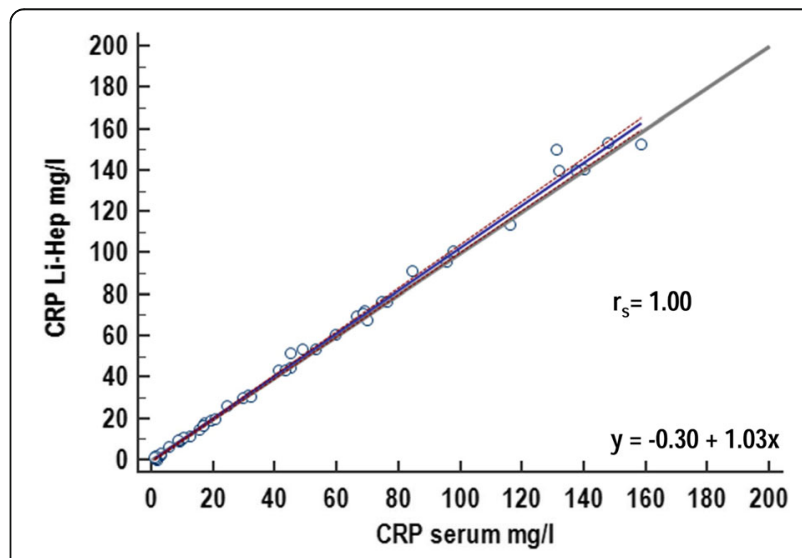

Fig. 4 Passing-Bablok regression analysis detailing the comparison between results of canine C-reactive protein (CRP) determined in either serum samples or lithium heparin samples (Li-Hep) with the Gentian Canine CRP Immunoassay. The solid blue line illustrates the regression with its 95\%-confidence intervals (brown dotted line). The diagonal grey line is consistent with the identity line 


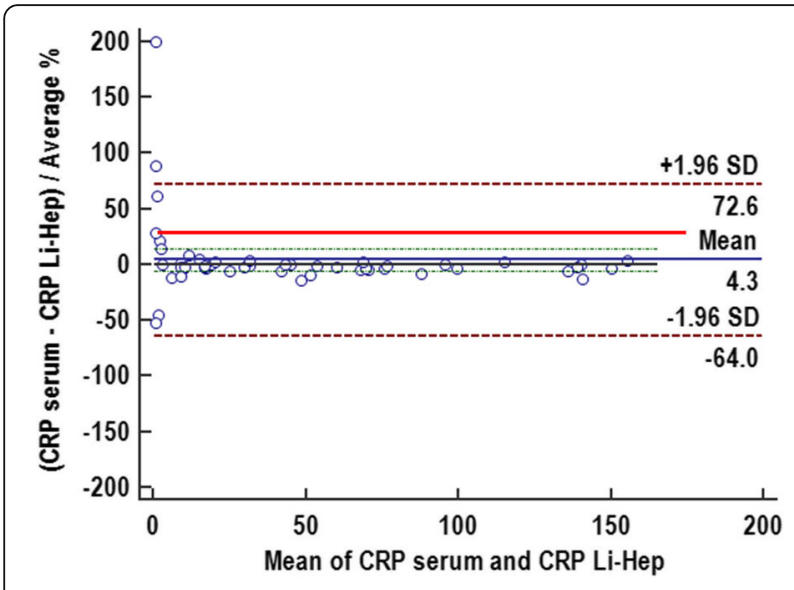

Fig. 5 Bland-Altman difference plot for canine C-reactive protein (CRP) measured in canine serum samples and canine lithium heparin (Li-Hep) samples with a Gentian Canine CRP Immunoassay. The black line is consistent with the zero line. The blue line indicates the mean bias and its 95\%-confidence interval (green dotted line). The dotted brown line is consistent with the \pm 1.96 standard deviation (SD) of the mean absolute bias indicating the limits of agreement. The red line indicates the desired maximum total allowable error ( $\left.\mathrm{TE}_{\mathrm{des}}\right)$ of 29.6\% [32] for measurement of canine CRP

$\mathrm{TE}_{\mathrm{des}}$ also published in the ACVCP guidelines. While both approaches are justified, it has to be considered that using the $\mathrm{TE}_{\mathrm{des}}$ - and thus both bias and CV - is a more stringent approach than just applying $\mathrm{CV}_{\text {des }}$ and is therefore the most likely explanation for the LoQ set at a higher CRP concentration than in the current study $(6.8 \mathrm{mg} / \mathrm{l}$ and $4.0 \mathrm{mg} / \mathrm{l}$, Table 6 ). When regarding the results published previously, a SD of $0.39 \mathrm{mg} / \mathrm{l}$ was observed at a CRP concentration of $6.8 \mathrm{mg} / \mathrm{l}$, consistent with a CV of $5.5 \%$ which would have fulfilled the quality goal of the current study. While a similar study design would have been preferable to allow an exact comparison between both analyzers and thus the true analyzer-dependent effect, both studies have been planned independently from each other in overlapping periods of time.

Possible contributing factors to differences between the studies might be also pre-analytical errors, especially due to pipetting as well as the impact of the analyzer. Also the LoQ determined by Muñoz-Prieto et al. is slightly higher (Table 6) which may be due to preanalytical or analyzer dependent conditions or influenced by the exact CRP levels used to evaluate the limit. However, the differences in LoQs observed in all three studies are rather academic in nature than of true clinical relevance as the clinical decision limit to differentiate between healthy dogs or dogs with and without systemic inflammation was $16.8 \mathrm{mg} / \mathrm{l}$ [38] and thus well above the LoQs found here and in the previous investigation.

For CRP concentrations above the LoQ of $4 \mathrm{mg} / \mathrm{l}$, intra-assay and inter-assay CVs ranging between 0.68$12.2 \%$ and $0.88-7.84 \%$ respectively were comparable to or lower than CVs reported in previous studies evaluating human assays for canine specimens. Evaluated human assays included the Bayer CRP assay (Bayer CRP TIA' Bayer plc, Newbury, Berkshire, United Kingdom: inter- and intra-assay CVs 5.2\% - 10.8\% and 3\% - 10.2\% [22]; the Randox CRP assay with human calibrator, Randox Laboratories Ltd., Crumlin, United Kingdom: interand intra-assay CVs with human calibrator: 1\% - 10\% and 18\% [23]; the Randox CRP assay with canine calibrator, Randox Laboratories Ltd., Crumlin, United Kingdom: intra-assay CV: $0.7 \%-2.1 \%$ (own unpublished data); and the Olympus CRP assay, CRP OSR 6147, Olympus Life and Material Science Europe GmbH, Lismeehan, O'Callaghan's Mills, Ireland 6147: inter- and intra-assay CVs: both $<10 \%$ [39]). When regarding solely canine species specific CRP assays, inter- and intra-assay CVs obtained for the Gentian CRP test here and in the previous investigation by Hillström et al. (Table 6) were markedly lower than for a commercially available canine CRP ELISA test kit and this can be attributed to the higher variation observed in manual methods (Phase Range canine CRP, Tridelta Development Ltd., Kildare, Republic of Ireland: inter- and intra-assay CVs: 6.9\% $10.1 \%$ and $7.5 \%-29 \%$ ) [18]. Muñoz-Prieto et al. showed a similarly low intra-assay CV of $1.0-1.3 \%$ for the Gentian CRP test at CRP ranges $\geq 50 \mathrm{mg} / \mathrm{l}$ and an only slightly higher inter-assay CV of 4.1-4.7\% (Table 6) still lying below the data of the ELISA test. For a previously developed automated immunoturbidimetric canine CRP assay, intra- and inter-assay CVs $<5 \%$ and $\leq 11 \%$, respectively [40] were reported which are comparable to the CVs found in the current and previous studies. The drawback of the previous canine CRP assay, however, was that it was never commercially available. For CRP concentrations $>26.5 \mathrm{mg} / \mathrm{l}$, the CVs reported in the previous study evaluating the Gentian Canine CRP Immunoassay on the Abbott Architect c4000 were comparable to our results obtained for the clinically relevant concentration levels B-D) (Table 6). For lower CRP concentrations, intra-assay CVs were not calculated in the previous method validation study by Hillström et al. However, an SD of $0.39 \mathrm{mg} / \mathrm{l}$ was obtained for a sample with a CRP concentration of $6.8 \mathrm{mg} / \mathrm{l}$ which was consistent with a CV of $5.7 \%$ and thus comparable to the interassay $\mathrm{CV}$ observed here for a similar CRP concentration level. The CV of $5.8 \%$ observed by Muñoz-Prieto et al. for a low CRP concentration of $\sim 10 \mathrm{mg} / \mathrm{l}$ was also comparable to our and the previous results. Excellent correlation for the Gentian CRP test with the compared assay was shown in the current and both previous studies (Table 6).

When regarding the rationale behind the method validation study performed here, assessment of $\mathrm{TE}_{\mathrm{obs}}$ is an essential point of each method comparison experiment 
Table 6 Comparison of observed quality parameters for the Gentian Canine CRP Immunoassay run on three different analyzers

\begin{tabular}{|c|c|c|c|}
\hline Quality parameters Gentian CRP & ABX Pentra 400 & Abbott Architect $c 4000^{a}$ & Olympus AU600 \\
\hline Limit of quantification (mg/l) & $4.0^{c}$ & $6,8^{d}$ & $5.4^{\mathrm{e}}$ \\
\hline Linearity (mg/l) & $4-281$ & $6.8-1201$ & $\sim 5-100$ \\
\hline Recovery (\%) & $90-105$ & $116-123$ & $105-118$ \\
\hline No prozone effect (mg/l) & $\leq 676$ & $\leq 1200$ & $\leq 400$ \\
\hline \multicolumn{4}{|l|}{ Precision } \\
\hline CRP range $(\mathrm{mg} / \mathrm{l})$ : & $<270 ;>25$ & $<270 ;>25$ & $\leq 100, \geq 50$ \\
\hline Intra-assay CV (\%) & $0.7-1.9$ & $0.5-1.7$ & $1.0-1.3$ \\
\hline \multicolumn{4}{|l|}{ Inter-assay CV (\%) } \\
\hline - Between run CV (\%) & $0.9-2.1$ & $0.0-0.3$ & n.d. \\
\hline - Between day CV (\%) & $1.1-4.6$ & $1.1-1.9$ & $4.1-4.7$ \\
\hline \multicolumn{4}{|l|}{ No Interference up to } \\
\hline - Hemoglobin (g/l) & 5 & 10 & n.d. \\
\hline - Bilirubin (mg/l) & 800 & n.d. & n.d. \\
\hline - Triglycerides (g/l) & 10 & 10 & n.d. \\
\hline \multicolumn{4}{|l|}{ Method comparison } \\
\hline Reference method & Randox Canine CRP assay & Randox Canine CRP assay & Olympus CRP \\
\hline$-r_{s}$ & 0.98 & 0.995 & 0.96 \\
\hline - intercept & -1.18 & 7.3 & n.d. \\
\hline - slope & 0.99 & 0.92 & n.d. \\
\hline - mean constant bias (\%) & 5.2 & n.d. & $41.0-70.5^{f}$ \\
\hline - $\mathrm{TE}_{\mathrm{obs}}(\%)(\sim \mathrm{CRP} 7-60 \mathrm{mg} / \mathrm{l})$ & $9.5-20.9$ & n.d. & $50.4-82.6^{f}$ \\
\hline$(\sim \mathrm{CRP}>100 \mathrm{mg} / \mathrm{l})$ & $7.0-8.9$ & n.d. & n.d \\
\hline Sample type comparison & small impact & n.d. & n.d. \\
\hline
\end{tabular}

The assay was evaluated independently on the ABX Pentra 400 and compared to the data of the previous validation on the Abbott Architect c4000 and on the Olympus AU600.

Abbreviations: $n$.d. not done, $C V$ coefficient of variation, $T E_{o b s}$ observed total allowable error

${ }^{a}$ (Hillström et al. 2014) ${ }^{b}$ (Muñoz-Prieto et al.2017) ${ }^{\mathrm{c}}$ based on the desirable $\mathrm{CV}<12.16 \%$, d based on desirable $\mathrm{TE}<29.58 \%$; both published in the addendum of the Total allowable error (TE) guidelines of the American College of Veterinary Clinical Pathology [32], ${ }^{e}$ based on CV $<20 \%$ (Escribano et al. 2012). ${ }^{f}$ calculated based on the data of healthy and diseased dogs evaluated by Muñoz-Prieto et al.: healthy dogs: bias $\%=\frac{\text { median control-median test }}{\text { mean of the medians }}=\frac{2.82 \frac{\mathrm{mg}}{\mathrm{T}}-1.35 \frac{\mathrm{mg}}{\mathrm{T}}}{(2.82-1.35): 2} \times 100 \% \approx 70.5 \%$;

$\mathrm{TE}_{\mathrm{obs}}=$ bias $\%+2 \mathrm{CV} \%=70.5 \%+2 \times 6.05 \%=82.6 \%$

dogs with inflammatory conditions: bias $\%=\frac{73.7 \frac{\mathrm{mg}}{\mathrm{T}}-48.6 \frac{\mathrm{mg}}{\mathrm{T}}}{(73.7+48.6): 2} \times 100 \% \approx 41.0 \% ; \mathrm{TE}_{\mathrm{obs}}=41.0 \%+2 \times 4.70 \%=50.4 \%$

[29]. In our study, observed CVs and TEs were lower than recommended desirable quality specification published in the addendum of the allowable total error guidelines of the ASVCP [32]. As the quality specifications published by the ASVCP are based on biological variation, they have been considered too stringent for method validation studies [32]. Nevertheless, they were used in this study as no other quality specifications are available for dogs. Even in human studies, quality specifications for CRP are based on biological variation. Interestingly, $\mathrm{TE}_{\text {des }}$ for CRP reported for people is $56.6 \%$ [41] and thus markedly higher than the recommended desirable $\mathrm{TE}_{\text {des }}$ given for dogs of $29.58 \%$ and even slightly higher than the recommended minimally acceptable TE for dogs of $44.37 \%$ [32]. Moreover, national recommendations are available for people such as the German RiliBÄK quality specifications (i.e., Guidelines (= RichtLinie
"Rili") of the German Federal Medical Council (= Bundesärztekammer "BÄK") [42], for which unofficial translations [43] have been performed to allow an international use. Overall, German RiliBÄK quality specifications are most stringent as only deviations of $13.5 \%$ are allowed. Interestingly, they are comparable with the recommended $\mathrm{TE}_{\mathrm{opt}}$ for canine CRP of $14.79 \%$ published in the ASVCP guidelines [32]. $\mathrm{TE}_{\mathrm{opt}}$ being comparable with German RiliBÄK quality specifications has been also observed previously for hematology measurands [44]. For CRP concentrations $>58 \mathrm{mg} / \mathrm{dl}, \mathrm{TE}_{\mathrm{obs}}$ was even below these most stringent quality specifications. For lower CRP concentrations close to physiologic values, $\mathrm{TE}_{\mathrm{obs}}$ was higher which was mainly based on a higher $\mathrm{CV}$. Despite all advantages of the calculation of $\mathrm{TE}_{\mathrm{obs}}$ (encompassing various sources of error by the inclusion of imprecision and bias) [45], it has to be considered 
that also the $\mathrm{TE}_{\mathrm{obs}}$ is not a perfectly objective quality parameter as it is dependent on the reference method used to calculate the bias as was shown before for hematology analyzers [44]. At the moment, there is no consensus about the methodology for bias determination for quality assessments. A high bias does not necessarily indicate a poor assay performance but might be solely induced by differences in the test protocol [46]. Only if the reference method can be considered as a current gold standard, a high bias has to be interpreted as a deficient quality performance. If the quality data of the current study are compared to the bias and $\mathrm{TE}_{\mathrm{obs}}$ calculated based on data of the previous method comparison with another human based CRP assay [28] at for clinical decisions relevant CRP levels, major differences can be detected which may mainly be due to the different reference method applied (Table 6). Hillström et al. [26] used the same reference assay as was used in our study but did not provide data for an estimation of the $\mathrm{TE}_{\mathrm{obs}}$. At the moment there is no superior alternative to the assessment of $\mathrm{TE}_{\mathrm{obs}}$. Even the use of the $\mathrm{TE}$ as quality standard is not without limitations as there are several methods of its determination (i.e, derived on experts' opinion, human quality specifications or biological variation [44]) which might come to different results. For the canine CRP, only a TE derived from biological variation is available, however, it has to be considered that the analytical method and the analyzer initially used for its determination have an impact on the results. Analysis of possible interferences of hemolysis, hyperbilirubinemia and lipemia on the assay performance revealed no interferences in clinically relevant concentrations up to $5 \mathrm{~g} / \mathrm{l}$ hemoglobin, $800 \mathrm{mg} / \mathrm{l}$ bilirubin and $10 \mathrm{~g} / \mathrm{l}$ soy bean oil (Intralipid). The absence of interference of lipemia and hemolysis with the CRP measurement was also confirmed in the previous study evaluating the speciesspecific Gentian Canine CRP Immunoassay [26] (Table 6), however, the potential interfering effect of bilirubin was not assessed previously. To the author's knowledge, this is the first time effects of hyperbilirubinemia are investigated on the Gentian Canine CRP Immunoassay. The lack of interference effects has to be claimed as a major advantage in CRP analysis as associated metabolic states frequently occur in patients with inflammatory and infectious diseases [26]. In contrast, significant interferences for all three substances were noted for a commercial solid phase sandwich immunoassay (Tridelta Phase Range Canine C-reactive Protein Assay; Tridelta Development, Bray, Ireland) although the low magnitude of the differences did not appear of relevance for clinical interpretation of the test [47].

To the authors' knowledge, the effect of the sample type (heparinized plasma as an alternative to serum) has not been evaluated before for the Gentian Canine CRP
Immunoassay. However, there are data available for the dog-specific CRP ELISA (Tridelta Phase Range Canine C-reactive Protein Assay, Tridelta Development, Bray, Ireland). As in our study, there was no major difference $(P=0.008)$ in CRP results measured in heparin plasma or serum, although in contrast to our findings, the results tended to be slightly but insignificantly higher in heparin plasma than in serum [47]. As CRP measurements in heparin plasma showed a similar $\mathrm{CV}$ than those performed in serum samples, it can be concluded that both heparin plasma and serum can be used. Due to the small bias, however, follow-up examinations should be ideally performed in the same sample type.

\section{Conclusion}

The results of this study are comparable to the findings observed during the previous evaluation of the canine species-specific CRP test run on different analyzers [26, 28]. The good performance of the test enables its application to several types of large bench top analyzers. However the discrepant findings between the current and previous studies such as the CRP concentration at which a prozone effect occurs, linearity range and LoQ should be specifically evaluated for each analyzer and laboratory performing the test.

\section{Acknowledgements}

We thank Julia Klotz (scil animal care company GmbH, Viernheim, Germany) for her contribution in sample measurements.

\section{Ethics approval}

The study was conducted in accordance with the German Animal Welfare Act (Article 8) and the competent authority was informed. According to the information of our ethics committee (Regierungspräsidium Giessen, Dezernat 54, Wetzlar, Germany, ethics committee number: Gl 17/18), a particular approval for the study was not needed, because the study itself was not the indication of blood sampling and did not require taking an additional amount of blood. The healthy dogs included in this study where presented in the Department of Veterinary Clinical Sciences in Giessen, Germany, either for annual health checks or blood donation. For the diseased dogs the measurement of CRP was part of the routine clinical chemical profile, whereby a $1.2 \mathrm{~cm}^{3}$ serum tube for measurement of CRP and a $1.2 \mathrm{~cm}^{3}$ heparin tube for measurement of the remainder clinical chemical measurands was required. In case of the samples obtained from the School of Veterinary Medicine, University of Liège, Liège, Belgium, only residual sample material was used.

\section{Funding}

The authors received the following financial support for the research, authorship, and/or publication of this article: Assay development was sponsored by the German Federal Ministry of Education and Research (promotional reference 01QE1110).

The Gentian Canine CRP Immunoassay including species-specific controls and calibrators was provided by Gentian AS, Moss, Norway.

\section{Availability of data and materials}

The datasets analyzed during the current study are available from the corresponding author on reasonable request.

\section{Competing interests}

SK and NK are working for scil animal care company GmbH, Viernheim, Germany which owns the distribution rights of the Gentian Canine CRP Immunoassay. The commercial interests of scil animal care company $\mathrm{GmbH}$ 
did not influence the presentation or interpretation of the results of the current study.SH, SZ, KG, NB and AM declare that they have no competing interests.

\section{Consent for publication}

Not applicable.

\section{Publisher's Note}

Springer Nature remains neutral with regard to jurisdictional claims in published maps and institutional affiliations.

\section{Author details}

${ }^{1}$ Department of Veterinary Clinical Sciences, Clinical Pathology and Clinical Pathophysiology, Justus-Liebig-University Giessen, 35392 Giessen, Germany. ${ }^{2}$ Scil animal care company GmbH, 68519 Viernheim, Germany. ${ }^{3}$ Department of Clinical Sciences, School of Veterinary Medicine, University of Liège, 4000 Liège, Belgium.

Received: 5 August 2016 Accepted: 18 May 2017

Published online: 30 May 2017

\section{References}

1. Higgins MA, Berridge BR, Mills BJ, Schultze AE, Gao H, Searfoss GH, et al. Gene expression analysis of the acute phase response using a canine microarray. Toxicol Sci. 2003;74:470-84.

2. Cerón JJ, Eckersall PD, Martínez-Subiela S. Acute phase proteins in dogs and cats: current knowledge and future perspectives. Vet Clin Pathol. 2005;34: 85-99.

3. Eckersall PD, Bell R. Acute phase proteins: biomarkers of infection and inflammation in veterinary medicine. Vet J. 2010;185:23-7.

4. Torrente C, Manzanilla EG, Bosch L, Fresno L, Rivera Del Alamo M, Andaluz $A$, et al. Plasma iron, $C$-reactive protein, albumin, and plasma fibrinogen concentrations in dogs with systemic inflammatory response syndrome. J Vet Emerg Crit Care (San Antonio). 2015;25:611-9.

5. Burton SA, Honor DJ, Mackenzie AL, Eckersall PD, Markham RJ, Horney BS. C-reactive protein concentration in dogs with inflammatory leukograms. Am J Vet Res. 1994;1994

6. Gebhardt C, Hirschberger J, Rau S, Arndt G, Krainer K, Schweigert FJ, et al. Use of C-reactive protein to predict outcome in dogs with systemic inflammatory response syndrome or sepsis. J Vet Emerg Crit Care (San Antonio). 2009;19:450-8.

7. McClure V, van Schoor M, Thompson PN, Kjelgaard-Hansen M, Goddard A. Evaluation of the use of serum C-reactive protein concentration to predict outcome in puppies infected with canine parvovirus. JAVMA (Journal of the American Veterinary Medical Association). 2013;243:361-6.

8. Martínez-Subiela S, Tecles F, Eckersall PD, Cerón JJ. Serum concentrations of acute phase proteins in dogs with leishmaniasis. Vet Rec. 2002;150:241-4.

9. Ulutas B, Bayramli G, Ulutas PA, Karagenc T. Serum concentration of some acute phase proteins in naturally occurring canine babesiosis: a preliminary study. Vet Clin Pathol. 2005;34:144-7.

10. K-w S, Lee J-b, Ahn J-O, Lee H-w, C-y H, H-y Y, et al. C-reactive protein as an indicator of inflammatory responses to experimentally induced cystitis in dogs. J Vet Sci. 2012;13:179-85.

11. Viitanen SJ, Laurila HP, Lilja-Maula LI, Melamies MA, Rantala M, Rajamäki MM. Serum C-reactive protein as a diagnostic biomarker in dogs with bacterial respiratory diseases. J Vet Intern Med. 2014;28:84-91.

12. Tecles F, Spiranelli E, Bonfanti U, Cerón JJ, Paltrinieri S. Preliminary studies of serum acute-phase protein concentrations in hematologic and neoplastic diseases of the dog. J Vet Intern Med. 2005;19:865-70.

13. Kjelgaard-Hansen $M$, Jensen $A L$, Houser $G A$, Jessen LR, Kristensen AT. Use of serum C-reactive protein as an early marker of inflammatory activity in canine type II immune-mediated polyarthritis: case report. Acta Vet Scand. 2006;48:9.

14. Bathen-Noethen A, Carlson R, Menzel D, Mischke R, Tipold A. Concentrations of acute-phase proteins in dogs with steroid responsive meningitis-arteritis. J Vet Intern Med. 2008;22:1149-56.

15. Nielsen L, Toft N, Eckersall PD, Mellor DJ, Morris JS. Serum C-reactive protein concentration as an indicator of remission status in dogs with multicentric lymphoma. J Vet Intern Med. 2007;21:1231-6.
16. Nakamura M, Takahashi M, Ohno K, Koshino A, Nakashima K, Setoguchi A, et al. C-reactive protein concentration in dogs with various diseases. J Vet Med Sci. 2008;70:127-31.

17. Dabrowski R, Wawron W, Kostro K. Changes in CRP, SAA and haptoglobin produced in response to ovariohysterectomy in healthy bitches and those with pyometra. Theriogenology. 2007;67:321-7.

18. Kjelgaard-Hansen M, Kristensen AT, Jensen AL. Evaluation of a commercially available enzyme-linked immunosorbent assay (ELISA) for the determination of C-reactive protein in canine serum. J Vet Med Series A. 2003;50:164-8.

19. Fransson BA, Bergström A, Wardrop KJ, Hagman R. Assessment of three automated assays for C-reactive protein determination in dogs. Am J Vet Res. 2007;68:1281-6.

20. Caspi D, Baltz ML, Snel F, Gruys E, Niv D, Batt RM, et al. Isolation and characterization of C-reactive protein from the dog. Immunology. 1984;53:307-13.

21. Yamamoto S, Miyaji S, Abe N, Otabe K, Furukawa E, NAIKI M. Canine Creactive protein (CRP) does not share common antigenicity with human CRP. Vet Res Commun. 1993;17:259-66.

22. Kjelgaard-Hansen M, Jensen AL, Kristensen AT. Evaluation of a commercially available human C-reactive protein (CRP) turbidometric immunoassay for determination of canine serum CRP concentration. Vet Clin Pathol. 2003;32:81-7.

23. Klenner S, Bauer N, Moritz A. Evaluation of three automated human immunoturbidimetric assays for the detection of C-reactive protein in dogs. J Vet Diagn Invest (Journal of Veterinary Diagnostic Investigation). 2010;22:544-52.

24. Kjelgaard-Hansen M. Comments on measurement of C-reactive protein in dogs. Vet Clin Pathol. 2010;39:402.

25. Skinner JG. International standardization of acute phase proteins. Vet Clin Pathol. 2001:30:2-7.

26. Hillström A, Hagman R, Tvedten H, Kjelgaard-Hansen M. Validation of a commercially available automated canine-specific immunoturbidimetric method for measuring canine C-reactive protein. Vet Clin Pathol. 2014;43:235-43.

27. Farr AJ, Freeman KP. Quality control validation, application of sigma metrics, and performance comparison between two biochemistry analyzers in a commercial veterinary laboratory. J Vet Diagn Investig. 2008;20:536-44.

28. Munoz-Prieto A, Tvarijonaviciute A, Escribano D, Martinez-Subiela S, Ceron JJ. Use of heterologous immunoassays for quantification of serum proteins: the case of canine C-reactive protein. PLoS One. 2017;12:1-14/14.

29. Jensen AL, Kjelgaard-Hansen M. Method comparison in the clinical laboratory. Vet Clin Pathol. 2006;35:276-86.

30. Armbruster DA, Pry T. Limit of blank, limit of detection and limit of quantitation. Clin Biochem Rev. 2008:49-52.

31. Gommeren K, Desmas I, Garcia A, Bauer N, Moritz A, Roth, J, Peeters, D. Inflammatory cytokines and C-reactive protein in canine systemic inflammatory response syndrome. J Vet Emerg Crit Care (San Antonio). in press.

32. Harr KE, Flatland B, Nabity M, Freeman KP. ASVCP guidelines: allowable total error guidelines for biochemistry. Vet Clin Pathol. 2013;42:424-36.

33. Jensen AL, Kjelgaard-Hansen M. Diagnostic test validation. In: Weiss DJ, Wardrop KJ, editors. Schalm's veterinary hematology. 6th ed. Ames: WileyBlackwell; 2010. p. 1027-33.

34. Andreasson U, Perret-Liaudet A, van Waalwijk van Doorn, Linda JC, Blennow K, Chiasserini D, Engelborghs S, et al. A practical guide to immunoassay method validation. Front Neurol. 2015;6:179.

35. American Society for Veterinary Clinical Pathology (ASVCP). Principles of quality assurance and standards for veterinary clinical pathology. 2009. [ http://www.asvcp.org/pubs/pdf/ASVCPQualityControlGuidelines.pdf ]. Accessed 25 May 2017.

36. Dodig S. Interferences in quantitative immunochemical methods. Biochem Med. 2009:50-62.

37. Gentian. Application Notes. http://gentian.no/products/canine-crp/ application-notes/. Accessed 25 May 2017.

38. Christensen MB, Langhorn R, Goddard A, Andreasen EB, Moldal E, Tvarijonaviciute $A$, et al. Comparison of serum amyloid a and C-reactive protein as diagnostic markers of systemic inflammation in dogs. Can Vet J. 2014:55:161-8.

39. Caldin M, Tasca S, Carli E, Bianchini S, Furlanello T, Martinez-Subiela S, et al. Serum acute phase protein concentrations in dogs with hyperadrenocorticism with and without concurrent inflammatory conditions. Vet Clin Pathol. 2009:38:63-8.

40. Eckersall PD, Conner JG, Harvie J. An immunoturbidimetric assay for canine C-reactive protein. Vet Res Commun. 1991;15:17-24.

41. Ricos C, Alvarez V, Cava F, Garcia-Lario J, Hernandez A, Jimenez C, et al. Desirable biological variation database specifications - Westgard. 2014. [https://www.westgard.com/biodatabase1.htm ]. Accessed 25 May 2017. 
42. Bundesärztekammer. Neufassung der „Richtlinie der Bundesärztekammer zur Qualitätssicherung laboratoriumsmedizinischer Untersuchungen - Rili-BÄK". Dtsch Arztebl. 2014;111.

43. Westgard S. Rilibak - German quidelines for quality - Westgard. 2015. [https://www.westgard.com/rilibak.htm ]. Accessed 25 May 2017.

44. Cook AM, Moritz A, Freeman KP, Bauer N. Quality requirements for veterinary hematology analyzers in small animals-a survey about veterinary experts' requirements and objective evaluation of analyzer performance based on a meta-analysis of method validation studies: bench top hematology analyzer. Vet Clin Pathol. 2016;

45. Lester S, Harr KE, Rishniw M, Pion P. Current quality assurance concepts and considerations for quality control of in-clinic biochemistry testing. J Am Vet Med Assoc. 2013;242:182-92.

46. Krouwer JS. Setting performance goals and evaluating Total analytical error for diagnostic assays. Clin Chem. 2002:919-27.

47. Martinez-Subiela S, Ceron JJ. Effects of hemolysis, lipemia,

hyperbilirubinemia, and anticoagulants in canine c-reactive protein, serum amyloid a, and ceruloplasmin assays. Can Vet J. 2005:625-9.

Submit your next manuscript to BioMed Central and we will help you at every step:

- We accept pre-submission inquiries

- Our selector tool helps you to find the most relevant journal

- We provide round the clock customer support

- Convenient online submission

- Thorough peer review

- Inclusion in PubMed and all major indexing services

- Maximum visibility for your research

Submit your manuscript at www.biomedcentral.com/submit
Biomed Central 